\title{
Effect of weather data aggregation on regional crop simulation for different crops, production conditions, and response variables
}

\author{
Gang Zhao ${ }^{1, *}$, Holger Hoffmann ${ }^{1}$, Lenny G. J. van Bussel ${ }^{1,2}{ }^{,}$Andreas Enders ${ }^{1}$, \\ Xenia Specka ${ }^{3}$, Carmen Sosa ${ }^{4}$, Jagadeesh Yeluripati ${ }^{5,19}$, Fulu Tao ${ }^{6}$, \\ Julie Constantin ${ }^{7}$, Helene Raynal $^{7}$, Edmar Teixeira ${ }^{8}$, Balázs Grosz ${ }^{9}$, Luca Doro $^{10}$, \\ Zhigan Zhao $^{11}$, Claas Nendel ${ }^{3}$, Ralf Kiese ${ }^{12}$, Henrik Eckersten ${ }^{13}$, Edwin Haas ${ }^{14}$, \\ Eline Vanuytrecht ${ }^{15}$, Enli Wang ${ }^{11}$, Matthias Kuhnert ${ }^{5}$, Giacomo Trombi ${ }^{18}$, \\ Marco Moriondo ${ }^{17}$, Marco Bindi ${ }^{18}$, Elisabet Lewan ${ }^{4}$, Michaela Bach ${ }^{9}$, \\ Kurt-Christian Kersebaum ${ }^{3}$, Reimund Rötter ${ }^{6}$, Pier Paolo Roggero ${ }^{10}$, \\ Daniel Wallach ${ }^{7}$, Davide Cammarano ${ }^{16}$, Senthold Asseng ${ }^{16}$, Gunther Krauss ${ }^{1}$, \\ Stefan Siebert ${ }^{1}$, Thomas Gaiser $^{1}$, Frank Ewert ${ }^{1}$
${ }^{1}$ Crop Science Group, Institute of Crop Science and Resource Conservation (INRES), University of Bonn, Katzenburgweg 5, 53115 Bonn, Germany
${ }^{2-19}$ Co-author addresses in the Supplement (www.int-res.com/articles/suppl/c065p141_supp.pdf)

\begin{abstract}
We assessed the weather data aggregation effect (DAE) on the simulation of cropping systems for different crops, response variables, and production conditions. Using 13 processbased crop models and the ensemble mean, we simulated $30 \mathrm{yr}$ continuous cropping systems for 2 crops (winter wheat and silage maize) under 3 production conditions for the state of North Rhine-Westphalia, Germany. The DAE was evaluated for 5 weather data resolutions (i.e. 1, 10, 25, 50 , and $100 \mathrm{~km}$ ) for 3 response variables including yield, growing season evapotranspiration, and water use efficiency. Five metrics, viz. the spatial bias $(\Delta)$, average absolute deviation (AAD), relative $A A D$, root mean squared error (RMSE), and relative RMSE, were used to evaluate the DAE on both the input weather data and simulated results. For weather data, we found that data aggregation narrowed the spatial variability but widened the $\Delta$, especially across mountainous areas. The DAE on loss of spatial heterogeneity and hotspots was stronger than on the average changes over the region. The DAE increased when coarsening the spatial resolution of the input weather data. The DAE varied considerably across different models, but changed only slightly for different production conditions and crops. We conclude that if spatially detailed information is essential for local management decision, higher resolution is desirable to adequately capture the spatial variability for heterogeneous regions. The required resolution depends on the choice of the model as well as the environmental condition of the study area.
\end{abstract}

KEY WORDS: Crop model $\cdot$ Model comparison $\cdot$ Spatial resolution $\cdot$ Data aggregation $\cdot$ Spatial heterogeneity $\cdot$ Scaling

\section{INTRODUCTION}

Process-based crop models are developed to simulate the interactions between plants, climate, soil, and management practices at a plot scale (Jones et al. 2003, Keating et al. 2003, van Ittersum et al. 2003, Holzworth et al. 2014). They mimic the dynamic responses of agricultural systems to environmental 
changes and anthropogenic influences such as the increasing concentration of $\mathrm{CO}_{2}$. Results of crop models can inform decision makers on policies relevant to food security and sustainability, and climate change mitigation and adaptation (Webber et al. 2014). The policies are normally made at administrative levels such as county, province, and country (Jones 1993, Glemnitz et al. 2011, Resop et al. 2014), and overall trends and spatial variability (e.g. hotspot areas that are particularly vulnerable to climate change) of the region are of particular interest to decision makers (Schulze 2000, Crossman \& Bryan 2009, Müller et al. 2014). To provide supporting information for these 2 aspects, input data and crop models need to be up-scaled to sufficiently represent the spatial variability of a region (Ewert et al. 2011).

Agro-ecosystems can display different magnitudes of spatial heterogeneity at regional or larger scales, because of the variability in the environmental conditions (climate and soil) and management practices. Applying crop models at corresponding scales requires geospatial data at a specific spatial resolution as input data and model parameters to capture the heterogeneity. The spatial resolution of the simulations is jointly determined by the availability of weather-soil-management data as well as the modeler's data handling and computing capacity (Zhao et al. 2013). In addition, all of the input data need to be aggregated or disaggregated to one consistent spatial resolution before executing a model. Many methods such as mean, weighted mean, majority, and central-pixel can be employed in data aggregation (Bian \& Butler 1999). No matter which method is used, a distortion of the original data cannot be avoided (Meentemeyer 1989). When the distorted data and parameters are used in the models, they affect the simulated results depending on the sensitivity of a model to the distortion (Bormann et al. 2009). Furthermore, for regions where high-resolution data are not available, the reliability of the coarse resolution simulation for decision making is often questioned. Such resolution and aggregation related issues can be referred to as the data aggregation effect (DAE).

Quantifying the DAE can improve the understanding of uncertainty resulting from the choice of spatial resolution of input data for cropping system simulations and related climate change impact assessments (Mearns et al. 1999, 2001, 2004, Zhao et al. 2015). DAE has been studied for different input data (e.g. soil, weather, and management), crops, response variables, production conditions, and various crop models (Van Bussel et al. 2011, Folberth et al. 2012, Angulo et al. 2013, Nendel et al. 2013,
Zhang et al. 2014, Eyshi Rezaei et al. 2015). Many methods such as frequency distribution (Angulo et al. 2013), visual comparison (Van Bussel et al. 2011, Zhang et al. 2014), and spatially absolute difference calculation (Folberth et al. 2012, Eyshi Rezaei et al. 2015, Zhao et al. 2015) were employed in these studies. These studies focused on a few aspects of the DAE with 1 or a limited number of models. The conclusions from these studies are diverse. Angulo et al. (2013) pointed out that uncertainty in yield simulation derived from the weather data aggregation was negligible compared to the uncertainty caused by the differences of 4 crop models. Van Bussel et al. (2011) concluded that weather and management data at coarse resolution $(100 \mathrm{~km})$ could be used to simulate the wheat phenology in Germany. Olesen et al. (2000) found that a $10 \mathrm{~km}$ or finer spatial resolution of input data can improve the simulation accuracy in modeling the winter wheat yields in Denmark. Mearns et al. (2004) and Di Vittorio \& Miller (2014) found that aggregation of weather data resulted in high uncertainty for simulation of crop yields at regional scales. Mummery \& Battaglia (2002) found that by using low-resolution input data, the mean productivity for large geographic extents can be biased, especially for regions with heterogeneous soil conditions. Zhao et al. (2015) found that the DAE was proportional to the spatial heterogeneity of environmental conditions of the study area in simulating winter wheat yield at the national scale of Germany.

The magnitude of the DAE on simulations may also depend on the non-linear relationships between specific response variable and input data (Mearns et al. 1999, Hansen \& Jones 2000). Non-linear relationships are frequently used to simulate crop responses to extreme events (e.g. frost damage and heat stress; Porter \& Semenov 2005), which are considered with threshold parameters in crop models (Eyshi Rezaei et al. 2015). Aggregation of weather data shortens the tails of the distribution, resulting in fewer extreme events (Durman et al. 2001, Eyshi Rezaei et al. 2015); consequently, as threshold parameters differ across crop models for different crops, the responses of different crop models to weather data aggregation are likely to be different. For example, Mearns et al. (1999) found that the CERES and EPIC models behaved differently when changing weather data from fine to coarse resolution in simulating corn yields. Easterling et al. (1998) found that higher spatial resolution of weather data improved the simulation accuracy for wheat but not for hay. However, previous studies have used a single or only a few models to 
investigate the DAE. Involving more models could help further clarify the role of crop models in the scaling effects and uncertainty. Moreover, equations and processes in the simulations differ when simulating different production conditions and different response variables. For instance, simulating potential yield requires fewer processes (mainly limited by temperature and solar radiation) than the yield under nitrogen+water limited production conditions (determined by weather, and limited by soil water and nitrogen availability). Even under a specific production condition and using a specific model, the sensitivity of a response variable to input data could vary when the parameterization of a model changes due to the interactions between the processes and the parameters. Tsvetsinskaya et al. (2003) pointed out that management options (e.g. irrigation and fertilization) could interact with the effect of changing spatial resolution of climate data. Although these questions have been frequently raised, a systematic evaluation to understand the DAE to guide the choice of spatial resolution in regional-scale studies is still pending.

Hence, we aimed to quantify the DAE (or the effect of changing the spatial resolution of weather input data) on simulated results, and to compare the DAE across a large ensemble of crop models, 3 response variables, 2 crops, and 3 production conditions. Using 13 process-based crop models at 5 spatial resolutions, we simulated yields and calculated evapotranspiration (ET) and water use efficiency (WUE) for 2 crops (winter wheat and silage maize) for the state of North Rhine-Westphalia (NRW), Germany - a temperatehumid region with pronounced differences in elevation. The spatial bias $(\Delta)$, average absolute deviation $(A A D)$, relative $A A D(r A A D)$, root mean squared error (RMSE), and relative RMSE (rRMSE) were used to quantify the DAE, while Hoffmann et al. (2015, this CR Special) quantified the DAE on the mean and median of all grid cells in the study area. Correlations between spatial heterogeneity of simulated variables and the DAE were also investigated.

\section{METHODS}

\subsection{Study area}

The study area was NRW, a state in the west of Germany (Fig. 1) that covers an area of $34084 \mathrm{~km}^{2}$. Nearly $50 \%$ of the state is located in the flat plains of the Westphalian Lowland and Rhineland, both of which extend broadly into the North German Plain.
The topography rises towards the south and east of the state and merges into Germany's Central Uplands. The elevation varies from 4 to $842 \mathrm{~m}$ above sea level. As agriculture is the most dominant land use type ( $>60 \%$ of the land area), we did not consider a land use mask in this study and simulations were conducted for the entire area.

\subsection{Climate and soil data}

Thirty years (1982-2011) of interpolated grid weather data including maximum, mean, and minimum temperature and sunshine hours at $1 \mathrm{~km}$ spatial resolution and monthly frequency were obtained from the German Meteorological Service (https://werdis. dwd.de/werdis/toBrowseTheme1.do). The description of procedures used to produce the monthly gridded weather data can be found in Kaspar et al. (2013). The number and spatial distribution of the weather stations for the different variables are shown in Fig. S1 in the Supplement, available at www.int-res.com/ articles/suppl/c065p141_supp.pdf. The solar radiation was calculated by Angstrom equations from the sunshine hours and Angstrom coefficients, which were calculated from a global dataset of radiation at relative low resolution $\left(0.5^{\circ}\right)$ (Posselt et al. 2011). This resulted in visually coarse grid cells at $1 \mathrm{~km}$ resolution

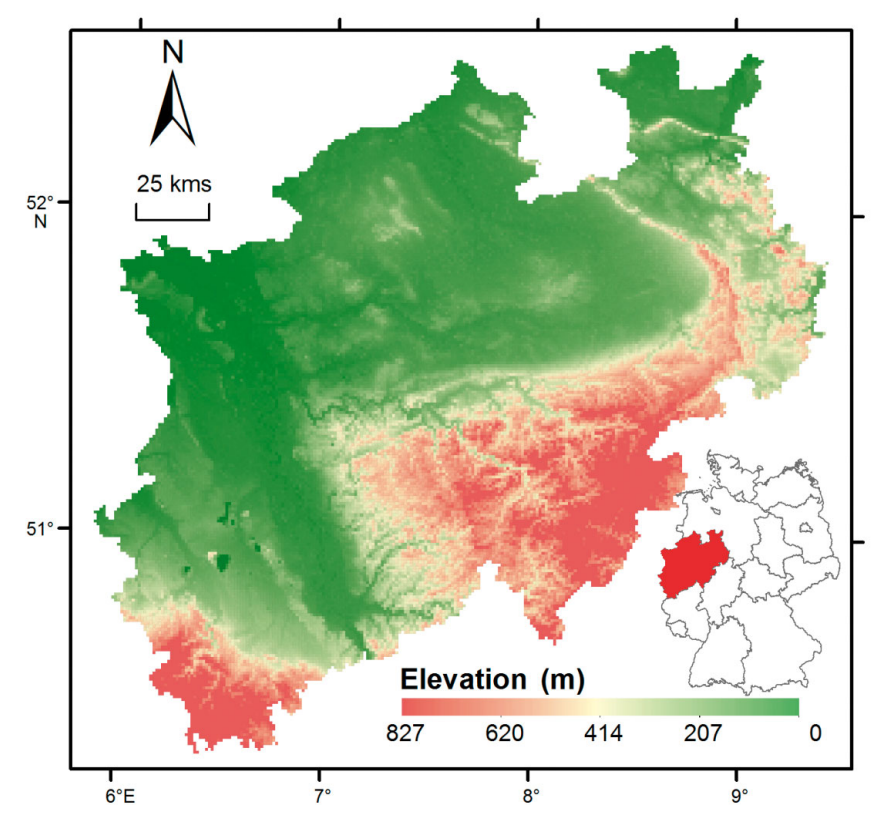

Fig. 1. Location and topography of the study area, North Rhine-Westphalia (NRW), Germany (data source: Federal Agency for Cartography and Geodesy, Germany, www. bkg.bund.de). The red area in the inset national map of Germany indicates the location of NRW 


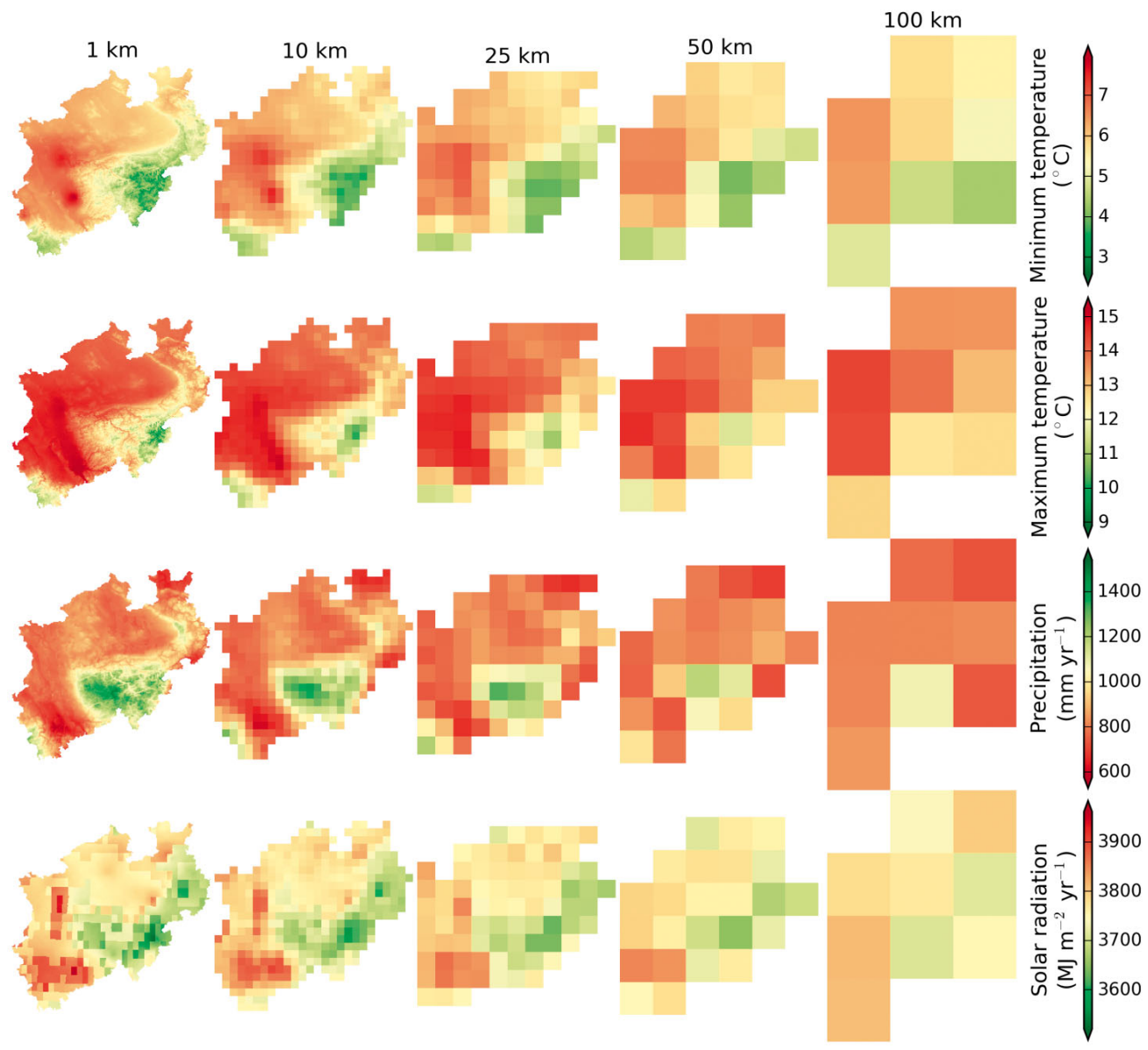

Fig. 2. Mean historical weather data in North Rhine-Westphalia (NRW), Germany, at 5 different spatial resolutions $(1,10$, 25, 50, and $100 \mathrm{~km}$ ). Each variable at different resolutions shares 1 color bar at the end of each row. The 2 temperature variables are daily minimum and maximum over $30 \mathrm{yr}$ (1982-2011). Precipitation and solar radiation are annual sums over the same period
(Fig. 2). Daily data from weather stations were then combined with the monthly grid data to increase the temporal resolution from monthly to daily (Siebert \& Ewert 2012). Daily precipitation sum at $1 \mathrm{~km}$ resolution was obtained directly from the German Meteorological Service (REGNIE dataset, http://werdis.dwd. de/werdis/retrieve_data.do?pidpat=de.dwd.hydromet. regnie.daily\&toplevel=true). In contrast to the other weather variables, the terrain was also considered in the interpolation of daily precipitation sum (Rauthe et al. 2013). The $1 \mathrm{~km}$ resolution data were then aggregated to the coarse resolutions $(10,25,50$, and $100 \mathrm{~km})$. The weather conditions for the study areas at 5 spatial resolutions are shown in Fig. 2. The detailed procedures for processing the weather data are described in Zhao et al. (2015).

The main focus of this paper was to study the effect of aggregation of weather data on the simulation outputs. Therefore, the potential influences from soil parameters were excluded by using a single 4-layer soil profile. The soil type represents the dominant soil in the cropland of NRW according to GDNRW (2001) (Table 1).

\subsection{Crop modeling}

Two crops (winter wheat and silage maize) were simulated under 3 production conditions (i.e. potential, water limited, and nitrogen+water limited). The typical management practices for this area were obtained from a farm planning handbook (Datensammlung KTBL 2008) and used to parameterize the phenology and management of the crop models. Winter wheat and silage maize were sown each year on 1 October and 20 April, respectively. Ninety percent of the aboveground biomass (grain yield and straw) was removed at harvest and the stubbles $(10 \%$ of aboveground biomass and roots) were left on the field. The maximum rooting depth was set at $1.5 \mathrm{~m}$ for both crops. A sowing depth of $4 \mathrm{~cm}$ and plant density of 400 plants $\mathrm{m}^{-2}$ were used for winter wheat; and a sowing depth of $6 \mathrm{~cm}$ and plant density of 10 plants $\mathrm{m}^{-2}$ were used for silage maize. Under nitrogen+water limited conditions, 130, 52, and $26 \mathrm{~kg} \mathrm{~N}$ ha $^{-1}$ were respectively applied on 1 March, 15 April, and 1 June for winter wheat; 30 and $208 \mathrm{~kg} \mathrm{~N} \mathrm{ha}^{-1}$ were respectively applied on 1 April and 1 June for silage maize. 
Table 1. Texture and properties of the 4-layer soil profile used to parameterize the soil part of the crop models. LD: layer depth $(\mathrm{cm})$; WP: soil water content at wilting point; AD: air-dry soil water content; FC: soil water content at field capacity; ST: soil water content at full saturation; $\mathrm{AC}$ : air capacity; IWC: initial soil water content; $\mathrm{BD}$ : bulk density; $\mathrm{C}_{\text {org }}$ : initial organic carbon; $\mathrm{C}: \mathrm{N}$ : carbon:nitrogen ratio

\begin{tabular}{|c|c|c|c|c|c|c|c|c|c|c|c|c|c|c|}
\hline Layer & $\begin{array}{l}\mathrm{LD} \\
(\mathrm{cm})\end{array}$ & $\begin{array}{c}\text { WP } \\
\left(\mathrm{m}^{3} \mathrm{~m}^{-3}\right)\end{array}$ & $\begin{array}{c}\mathrm{AD} \\
\left(\mathrm{m}^{3} \mathrm{~m}^{-3}\right)\end{array}$ & $\left(\mathrm{m}^{3} \mathrm{~m}^{-3}\right)$ & $\begin{array}{c}\mathrm{FC} \\
\mathrm{ST}\left(\mathrm{m}^{3} \mathrm{~m}^{-3}\right)\end{array}$ & $\begin{array}{c}\mathrm{AC} \\
\left(\mathrm{m}^{3} \mathrm{~m}^{-3}\right)\end{array}$ & $\begin{array}{l}\text { IWC } \\
(\mathrm{mm})\end{array}$ & $\begin{array}{l}\text { Clay } \\
(\%)\end{array}$ & $\begin{array}{l}\text { Silt } \\
(\%)\end{array}$ & $\begin{array}{c}\text { Sand } \\
(\%)\end{array}$ & $\begin{array}{c}\mathrm{BD} \\
\left(\mathrm{g} \mathrm{m}^{-2}\right)\end{array}$ & $\begin{array}{l}\mathrm{C}_{\text {org }} \\
(\%)\end{array}$ & $C: N$ & $\mathrm{pH}$ \\
\hline 1 & 30 & 0.17 & 0.085 & 0.36 & 0.45 & 0.09 & 57 & 24 & 60 & 16 & 1.4 & 2.76 & 17.2 & 6.2 \\
\hline 2 & 90 & 0.17 & 0.085 & 0.36 & 0.45 & 0.09 & 171 & 24 & 60 & 16 & 1.4 & 0.38 & 6.4 & 6.6 \\
\hline 3 & 80 & 0.13 & 0.065 & 0.37 & 0.44 & 0.07 & 192 & 14 & 75 & 11 & 1.4 & 0.27 & 6.9 & 6.8 \\
\hline 4 & 30 & 0.01 & 0.005 & 0.04 & 0.11 & 0.07 & 9 & 3 & 7 & 90 & 1.4 & 0.25 & 6.9 & 7.0 \\
\hline
\end{tabular}

Average reported harvest dates and yields in NRW for the 2 crops were provided to the modeling groups and used to calibrate the models. The average reported harvest date and yield of dry matter for winter wheat were 1 August and $7.2 \mathrm{t} \mathrm{ha}^{-1}$. The common reported harvest date and yield of dry matter for silage maize were 20 September and $14.3 \mathrm{t} \mathrm{ha}^{-1}$ (https:// www.regionalstatistik.de/genesis/online/logon).

The simulated dry matter yield (t ha ${ }^{-1}$, grain for winter wheat and aboveground biomass for silage maize), growing season evapotranspiration (ET, $\mathrm{mm}$ ), and water use efficiency (WUE, $\mathrm{kg} \mathrm{m}^{-3}$ ) were used as the response variables. WUE was calculated as the ratio of yield to ET over the growing season.

Thirteen process-based crop models (12 for winter wheat and 10 for silage maize), viz. APSIM (Keating et al. 2003, Holzworth et al. 2014), APSIM-Nwheat (Asseng et al. 1998, 2004), APSIMmodified (Wang et al. 2002, Keating et al. 2003), AquaCrop (Raes et al. 2009, Steduto et al. 2009, Vanuytrecht et al. 2014), COUP (Jansson 2001, Conrad \& Fohrer 2009), DayCent (Del Grosso et al. 2006, Yeluripati et al. 2009), EPIC (Williams et al. 1983, Williams 1995), HERMES (Kersebaum 2007, 2011), LandscapeDNDC (Haas et al. 2013, Kraus et al. 2015), SIMPLACE<LINTUL> (Gaiser et al. 2013, Zhao et al. 2015), MCWLA (Tao et al. 2009, Tao \& Zhang 2013), MONICA (Nendel et al. 2013), and STICS (Brisson et al. 1998, Bergez et al. 2013), were involved in this study. The description of these models can be found in Table S1 in the Supplement. For each production condition and each crop, the total number of simulations was 34691 (34 168, 410, 80, 24, and 9 for 1, 10, 25, 50 and $100 \mathrm{~km}$, respectively). Average results across all the models (ensemble mean) were computed and presented. The simulated yield of the ensemble mean was compared with observed yields from 1999-2011 (Fig. S2).

\subsection{Quantifying the effect of aggregating weather data}

The weather data at coarse resolutions were produced through spatial data aggregation (Fig. 3). Aggregation was conducted by taking the mean of the grid cells of $1 \mathrm{~km}$ resolution covered by the coarser resolution grid cell. The aggregation was applied to the daily weather data, which were then used as inputs into the crop models.

In the aggregation, the coarser-resolution data use one value to represent many higher-resolution values, thus the bias $(\Delta)$ could be calculated (Fig. 4$)$. The values at the highest resolution $(1 \mathrm{~km})$ were treated

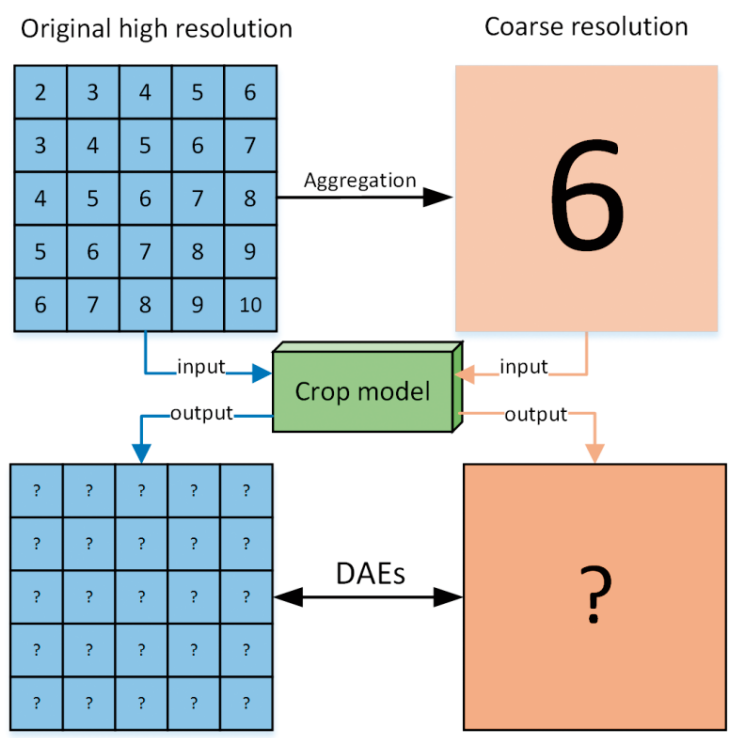

Fig. 3. Illustration of data aggregation and the data aggregation effect (DAE) for input and output data (modified after Zhao et al. 2015). The original high-resolution data (upper left) refers to the daily weather data at $1 \mathrm{~km}$ resolution; these data are aggregated to produce the coarse resolutions (upper right). Both sets were used to drive the crop models. The difference between the results of the 2 resolutions is the input DAE 


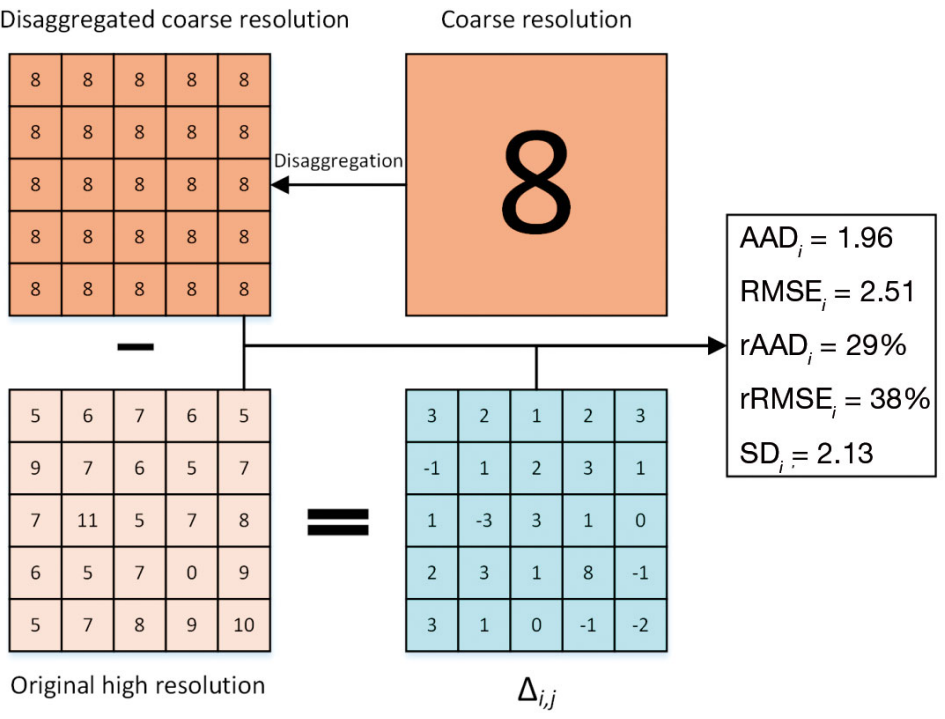

Fig. 4. Illustration of the disaggregation method and quantification of the data aggregation effect (DAE; modified after Zhao et al. 2015). The coarse-resolution data (upper right) refer to simulated results at coarse resolution. They are disaggregated to the high-resolution data set (upper left). The difference between the disaggregated results and the results directly simulated by the high-resolution input data (lower left) is named delta $(\Delta$, lower right). The metrics used to quantify DAE in the example are calculated according to Eqs. (1-5) where $n$ is the number of grid cells of the highest resolution $(1 \mathrm{~km})$. The $\mathrm{AAD}_{i}$ and $\mathrm{RMSE}_{i}$ indicate the average effect for variable $i$ for the whole study area. For example, if the $\mathrm{AAD}_{i}$ or $\mathrm{RMSE}_{i}$ for simulated yield equals $1 \mathrm{tha}^{-1}$, then data aggregation causes $1 \mathrm{t} \mathrm{ha}^{-1}$ bias in simulated yield on average. In addition, $\mathrm{RMSE}_{i}$ puts more weight on large differences because of the square of the differences. Hence, the RMSE is capable of capturing the change in hotspot areas, whereas the AAD is capable of capturing the change in average conditions (Davis \& Dodd 2003). The mean of the simulated response variables differed across crop models and 2 crops. To be comparable across models and crops, we further calculated the relative values of $\mathrm{AAD}$ and RMSE for the response variables as:

$$
\begin{aligned}
\operatorname{rAAD}_{i} & =\frac{\mathrm{AAD}_{i}}{\overline{\mathrm{OH}_{i}}} \times 100 \\
\mathrm{rRMSE}_{i} & =\frac{\mathrm{RMSE}_{i}}{\overline{\mathrm{OH}_{i}}} \times 100
\end{aligned}
$$

as 'true,' and $\Delta$ was quantified by taking the difference between values at coarse resolutions $(10,25,50$, and $100 \mathrm{~km}$ ) and the highest resolution (1 km) (Eq. 1). Since grid cell numbers of the different resolutions differed, the metrics could not be directly calculated. Thus the coarser resolution data were first disaggregated to the high resolution (Fig. 4).

We calculated $\Delta$ as:

$$
\Delta_{i, j}=\mathrm{DC}_{i, j}-\mathrm{OH}_{i, j}
$$

where $i$ indicates different variables (weather and response variable), $j$ indicates different grid cells, the $D C_{i, j}$ is the disaggregated value for a specific grid cell $j$ of variable $i, \mathrm{OH}_{i, j}$ is the original value at $1 \mathrm{~km}$ resolution for grid cell $j$ of variable $i$. The $\Delta_{i, j}$ aimed to quantify the spatial difference introduced by the weather data aggregation, but could not reveal the overall change for the whole study area (Willmott \& Matsuura 2005). We therefore calculated 2 metrics, the AAD and RMSE, to generalize the bias for the whole study areas. The AAD was calculated as:

$$
\mathrm{AAD}_{i}=\frac{\sum_{j=0}^{n}\left|\Delta_{i, j}\right|}{n}
$$

The RMSE was calculated as:

$$
\operatorname{RMSE}_{i}=\sqrt{\frac{\sum_{j=0}^{n} \Delta_{i, j}^{2}}{n}}
$$

where $\overline{\mathrm{OH}_{i}}=\frac{\sum_{j=1}^{n} \mathrm{OH}_{i, j}}{n}$, which is the mean of the variable $i$ across all the grid cells $(j)$ for a specific model, and $n$ is the number of grid cells. The unit for rAAD and rRMSE is percentage (\%).

\subsection{Relationship between spatial heterogeneity and DAE}

To test the hypothesis that the increasing heterogeneity of response variables increases the DAE, we correlated the spatial heterogeneity of simulated results with the DAE. We quantified the spatial heterogeneity of the simulated results for each model, each production condition, each crop, and each response variable by the standard deviation (SD) of all the grid cells at $1 \mathrm{~km}$ resolution.

$$
\begin{gathered}
\mathrm{SD}_{i}=\sqrt{\frac{\sum_{j=1}^{j=n}\left(\mathrm{OH}_{i, j}-\overline{\mathrm{OH}_{i}}\right)}{n}} \\
\overline{\mathrm{OH}_{i}}=\frac{\sum_{j=1}^{n} \mathrm{OH}_{i, j}}{n}
\end{gathered}
$$

where $n$ is the number of grid cells at $1 \mathrm{~km}$ resolution (34 168 for NRW), $i$ indicates different response variables, and $j$ indicates different grid cells at 


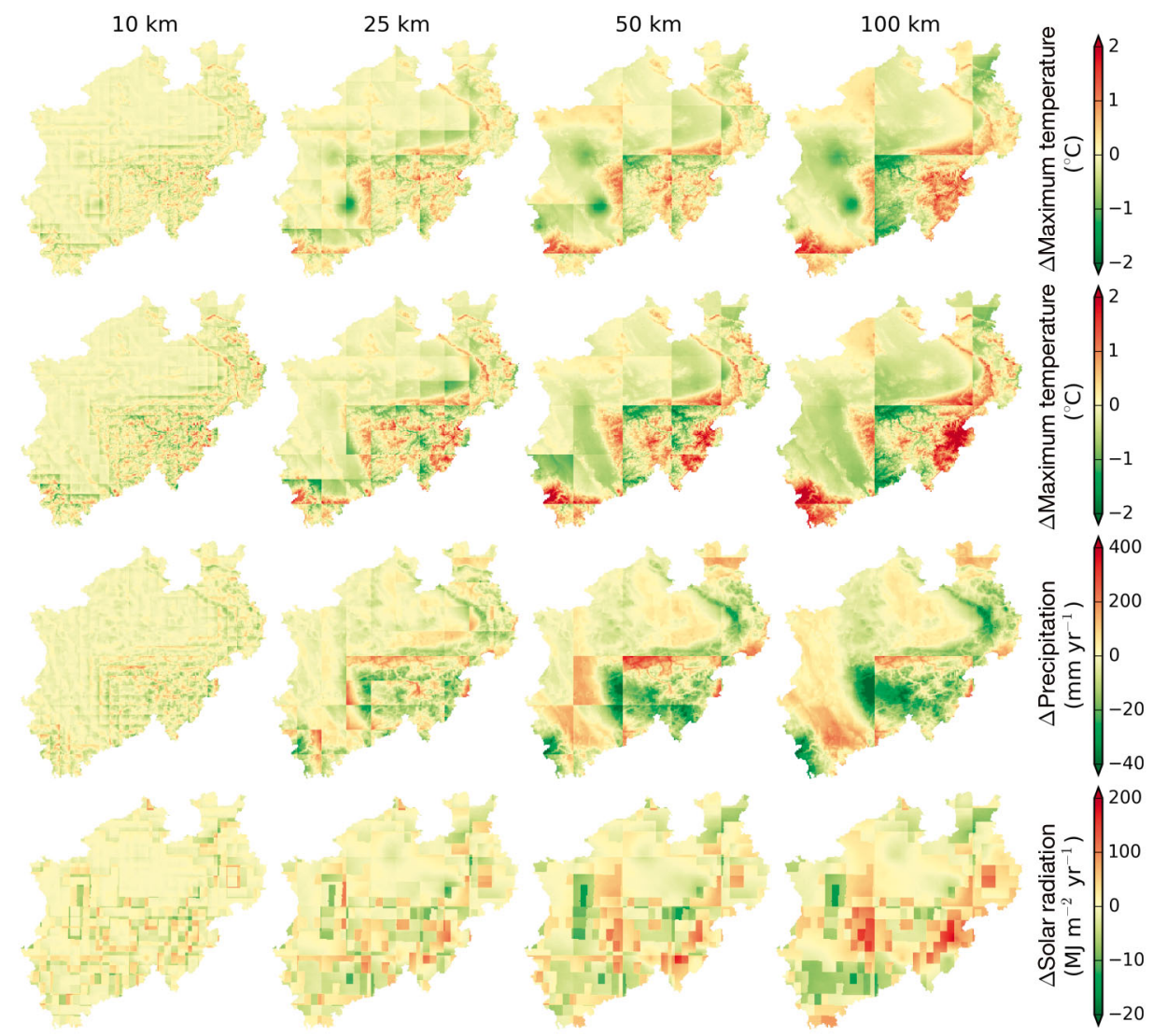

Fig. 5. Bias $(\Delta)$ of the historical weather variables (1982-2011) caused by data aggregation. $\Delta$ was calculated according to Eq. (1). The weather variables from top to bottom are minimum and maximum temperature, mean annual precipitation, and mean annual solar radiation, with a bias of 10, 25, 50, and $100 \mathrm{~km}$ (from left to right)

$1 \mathrm{~km}$ resolution. The spatial heterogeneity of the $1 \mathrm{~km}$ results was then regressed and plotted against the DAE.

\section{RESULTS}

\subsection{Aggregation effect on historical mean weather data}

The aggregation-caused $\Delta$ of all 4 weather variables notably increased with decreased spatial resolution, especially in the southwestern mountainous regions (Fig. 5). The $\Delta_{\text {precipitation }}$ ranged roughly from -400 to $400 \mathrm{~mm} \mathrm{yr}^{-1}, \Delta_{\text {maximum temperature }}$ from -3 to $3^{\circ} \mathrm{C}, \Delta_{\text {minimum temperature }}$ from -2 to $2^{\circ} \mathrm{C}$, and $\Delta_{\text {solar radiation }}$ from -200 to $200 \mathrm{MJ} \mathrm{m}^{-2} \mathrm{yr}^{-1}$. The spatial pattern of bias for radiation differed from other variables in that the values did not increase much from 50 to $100 \mathrm{~km}$ resolution. The signs of the bias values for precipitation were opposite to the other 3 variables.
Consistent with the spatial $\Delta$, the RMSE and AAD continually increased when the resolution became coarser (Table 2). The AAD varied in the same direction as RMSE but with lower values.

\subsection{Aggregation effect on simulated response variables}

Spatial patterns of simulated wheat yields under the 3 different production conditions and for different resolutions are shown in Fig. 6. The ensemble means show high yields in the northern and western flat lowland regions and lower yields in the southern and southeastern mountainous regions (Fig. 6). This was consistent for the different production conditions and for the different resolutions. At high resolution $(1 \mathrm{~km})$ and under the nitrogen+water limited production conditions, the simulated spatial patterns and variations were consistent with the historically mean observed yields from 1999-2011 (Fig. S2a). In the lowyielding regions, simulated potential yields were 
Table 2. Data aggregation effect, indicated by the root mean squared error (RMSE) and average absolute deviation (AAD, in parentheses) for historical (1982-2011) minimum temperature, maximum temperature, mean annual precipitation, and mean annual solar radiation

\begin{tabular}{|lcccc|}
\hline \multirow{2}{*}{ Weather data } & \multicolumn{4}{c|}{ RMSE (AAD) } \\
& $10 \mathrm{~km}$ & $25 \mathrm{~km}$ & $50 \mathrm{~km}$ & $100 \mathrm{~km}$ \\
\hline Minimum temperature $\left({ }^{\circ} \mathrm{C}\right)$ & $0.20(0.14)$ & $0.31(0.22)$ & $0.40(0.30)$ & $0.52(0.39)$ \\
Maximum temperature $\left({ }^{\circ} \mathrm{C}\right)$ & $0.29(0.19)$ & $0.42(0.29)$ & $0.54(0.39)$ & $0.66(0.48)$ \\
Precipitation $\left(\mathrm{mm} \mathrm{yr}^{-1}\right)$ & $44.57(31.74)$ & $74.01(52.54)$ & $106.81(75.58)$ & $119.76(85.57)$ \\
Solar radiation $\left(\mathrm{MJ} \mathrm{m}^{-2} \mathrm{yr}^{-1}\right)$ & $23.33(15.59)$ & $33.37(24.07)$ & $41.68(30.37)$ & $49.27(36.21)$ \\
\hline
\end{tabular}

and lower yields in the southeastern mountainous regions (Fig. 7). The contrast between high and low simulated maize yields is much stronger than for wheat (Fig. 6). At $1 \mathrm{~km}$ resolution, in the low-yielding regions, the simulated potential yields were around $12.0 \mathrm{t} \mathrm{ha}^{-1}$ and

around $7 \mathrm{tha}^{-1}$, while the nitrogen and water availability limited the simulated yields to less than $5 \mathrm{t}$ $\mathrm{ha}^{-1}$. The simulated low-yielding hotspot areas gradually disappeared with the coarsening of the resolution regardless of production conditions. The simulated yields decreased moderately when water and nitrogen stresses were included. This was consistent for all spatial resolutions.

Consistent with the spatial pattern of the historically observed yields of silage maize (Fig. S2b), the simulated ensemble mean showed higher yields for silage maize in the northwestern lowland regions the simulated yields limited by the availability of nitrogen+water stress were reduced to less than $8.5 \mathrm{t}$ $\mathrm{ha}^{-1}$. The low-yield areas disappeared at the $100 \mathrm{~km}$ resolution for all 3 production conditions. The differences between the simulated potential yields and water-limited yields were smaller than the difference between the simulated water-limited and nitrogenlimited yields.

When aggregating the weather data from high to coarse resolutions, the rRMSE and rAAD increased for the 2 crops, for all 13 models and the model ensemble mean (Figs. 8 \& S3). The increases differed

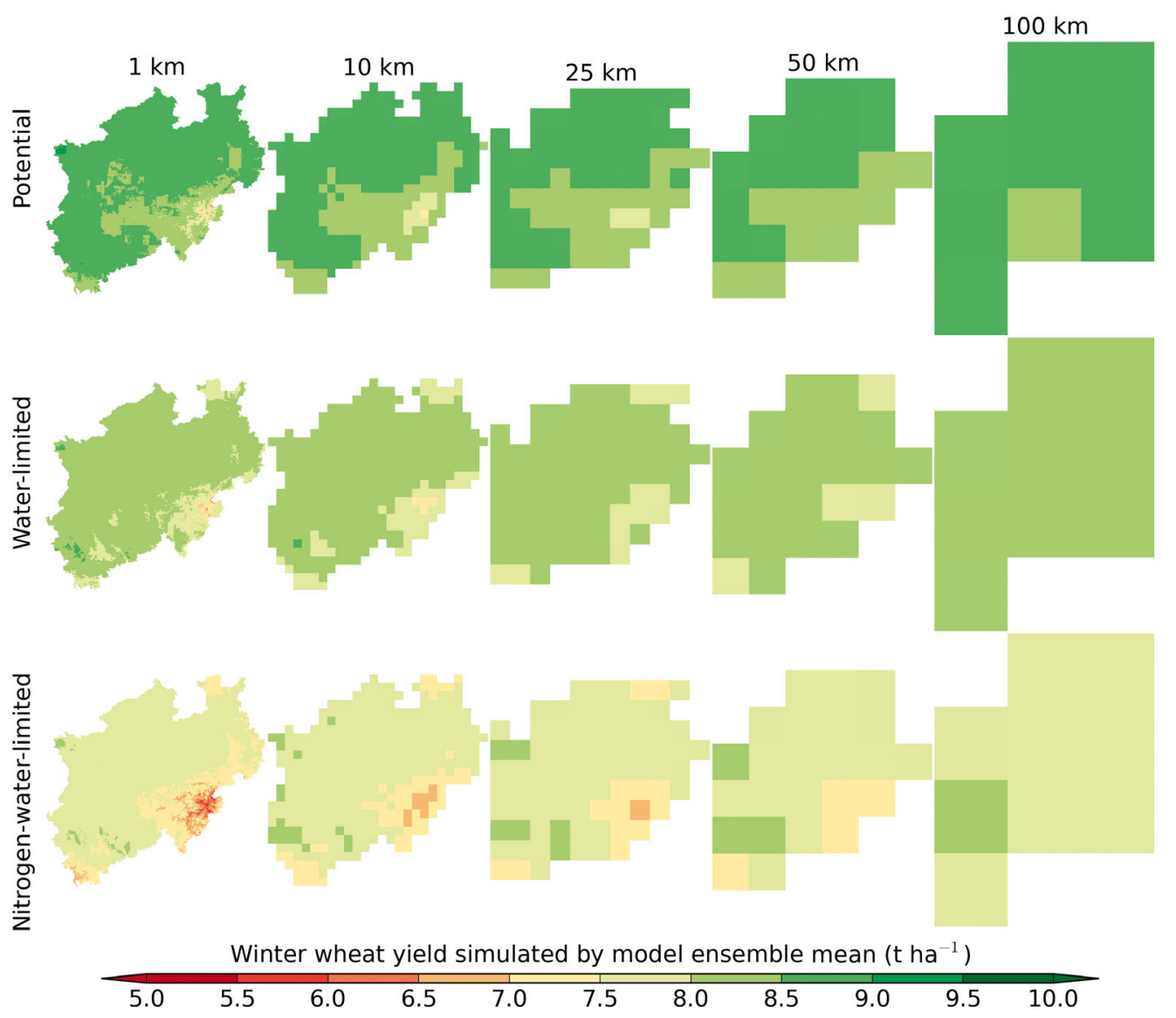

Fig. 6. Simulated yield of winter wheat (ensemble mean, average over all models from 1982-2011) for 5 resolutions $(1,10$, 25, 50, and $100 \mathrm{~km}$ ) and 3 production conditions, i.e. potential, water limited, and nitrogen+water limited 
considerably across models and 3 response variables. The increase in rRMSE and rAAD at coarse resolutions was larger (i.e. steeper slopes of the response) from 10 to $50 \mathrm{~km}$ than from 50 to $100 \mathrm{~km}$. The highest rRMSE for winter wheat yield and WUE is $>12 \%$ (outputs from LandscapeDNDC), and for silage maize yield and WUE about $10 \%$. For 1 specific model, the ranks of rRMSE for the same model were not consistent for different response variables, e.g. the rRMSE of DNDC for winter wheat yield was the highest across all the models but was one of the lowest for the growing season ET.

The rRMSE and rAAD varied only slightly across the 3 different production conditions for the 2 crops (Fig. 9). The ranges of the rRMSE median were between 2.5 and $4.2 \%$. The rRMSEs for yield increased when the crops were stressed due to water shortage, but decreased when the crops were further stressed due to nitrogen limitations. The rRMSEs for yield of silage maize were larger than for winter wheat, while the rRMSEs for the other 2 variables were similar for the 2 crops. Generally, the rAADs were smaller than rRMSEs, and also did not vary much across the 3 production conditions.

\subsection{Relationship between DAE and spatial heterogeneity}

The DAE significantly increased in proportion to the spatial heterogeneity of the simulated response variables (SD of simulated results across all grid cells) at $1 \mathrm{~km}$ for each response variable (Fig. 10 and see Figs. S8 \& S9 for winter wheat and silage maize, respectively). The relationship was stronger for the simulated yield than for the other 2 response variables (ET and WUE). Coarser spatial resolution was associated with stronger DAE for most of the models. The differences across different production conditions were small.

\section{DISCUSSION}

Information about the required spatial resolution for regional impact assessments is important. Highresolution data could capture spatial variability but at the cost of intensive computing and data management. Simulations at coarse resolution demand less computing power at the cost of losing the spatial vari-
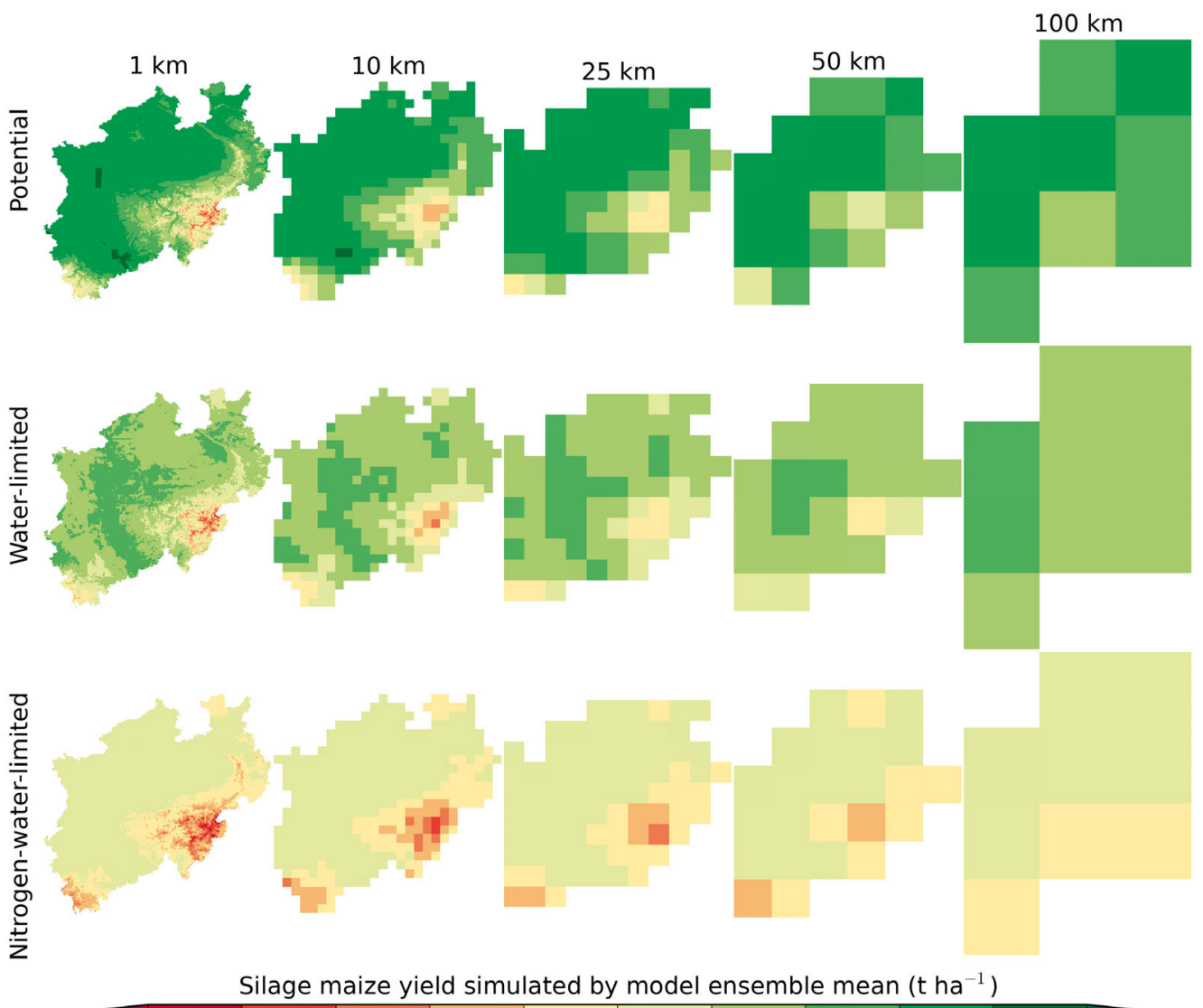

Silage maize yield simulated by model ensemble mean ( $\mathrm{t} \mathrm{ha}^{-1}$ )

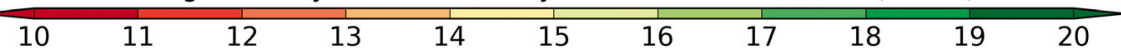

Fig. 7. Simulated silage maize yield by ensemble mean (average over all models from 1982-2011) at 5 resolutions $(1,10$, 25, 50, and $100 \mathrm{~km}$ ) and 3 production conditions, i.e. potential, water limited, and nitrogen+water limited 


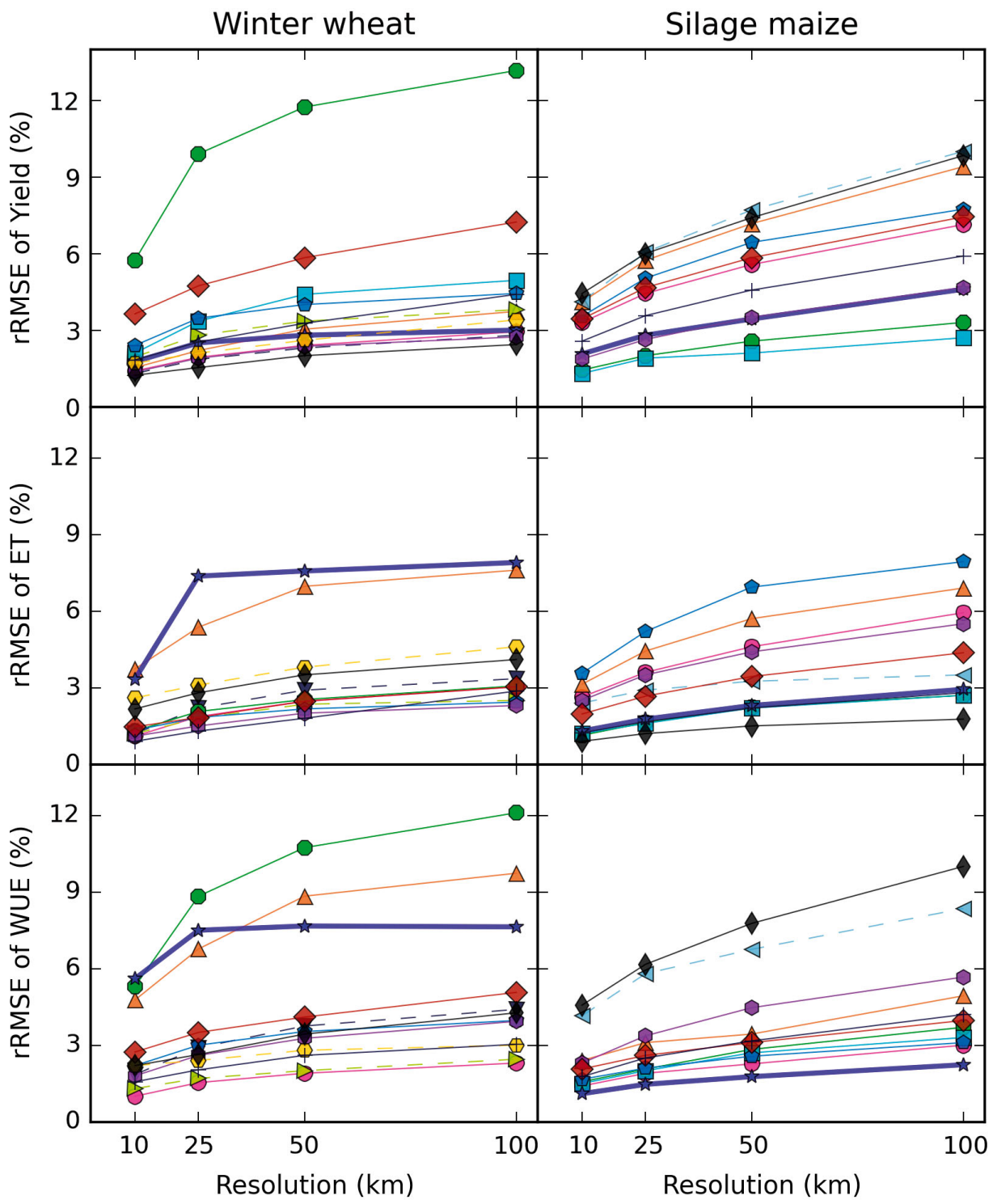

\begin{tabular}{|ll|}
\hline- & APSIM \\
$-\nabla$ & APSIM-NWHEAT \\
$\triangle$ & APSIM_Modified \\
- & AquaCrop4.0 \\
$\square$ & COUP \\
- & LandscapeDNDC \\
$\square$ & DayCent \\
- & EPIC \\
- & Ensemble mean \\
- & HERMES \\
- & MCWLA \\
$\triangleright$ & MONICA \\
- & SIMPLACE <LINTUL> \\
+ & STICS
\end{tabular}

Fig. 8. Weather data aggregation effect on simulated yield, evapotranspiration (ET), and water use efficiency (WUE), indicated by the relative root mean squared error (rRMSE) compared to the $1 \mathrm{~km}$ resolution. The RMSE is relative to the mean of the variable across all grid cells for a specific model. Values shown are the means of rRMSE in 3 production conditions. Solid lines were used for models that simulated both winter wheat and maize, while dashed lines were used for models that simulated only 1 crop ability within coarse-resolution pixels. For the first time, a systematic analysis was performed to quantify DAE for weather input data across scales and study how they depend on crop type, production condition, response variable, and crop model.

\subsection{Performance of the crop models and ensemble mean}

In this study, the models were independently calibrated by different crop modelers based on limited information about the mean growing period (sowing and harvest dates) and crop yields over the last decade as the average over the whole study area. After calibration, the majority of models that were used (only the mean of 1 model had $>20 \%$ bias) could closely simulate the observed mean yield under nitrogen+water limited conditions. The yields of winter wheat and silage maize of the model ensemble mean were comparable to the observed yields with respect to both spatial patterns and variation ranges at $1 \mathrm{~km}$ resolution (Figs. 6, 7, \& S2). The good performance of the model ensemble mean is in line with many other studies that used the crop model ensemble (Palosuo et al. 2011, Rötter et al. 2011, Asseng et al. 2013, 2015, Falloon et al. 2014).

In contrast to the good performance of the ensemble mean, spatial patterns of simulated yields differed across models. In some cases, simulated patterns were in the opposite direction across models (Figs. S4 $\&$ S5). The reason for this could be the different sensitivity of models to weather variables (Eitzinger et al. 2013, Watson \& Challinor 2013). To confirm this, we 


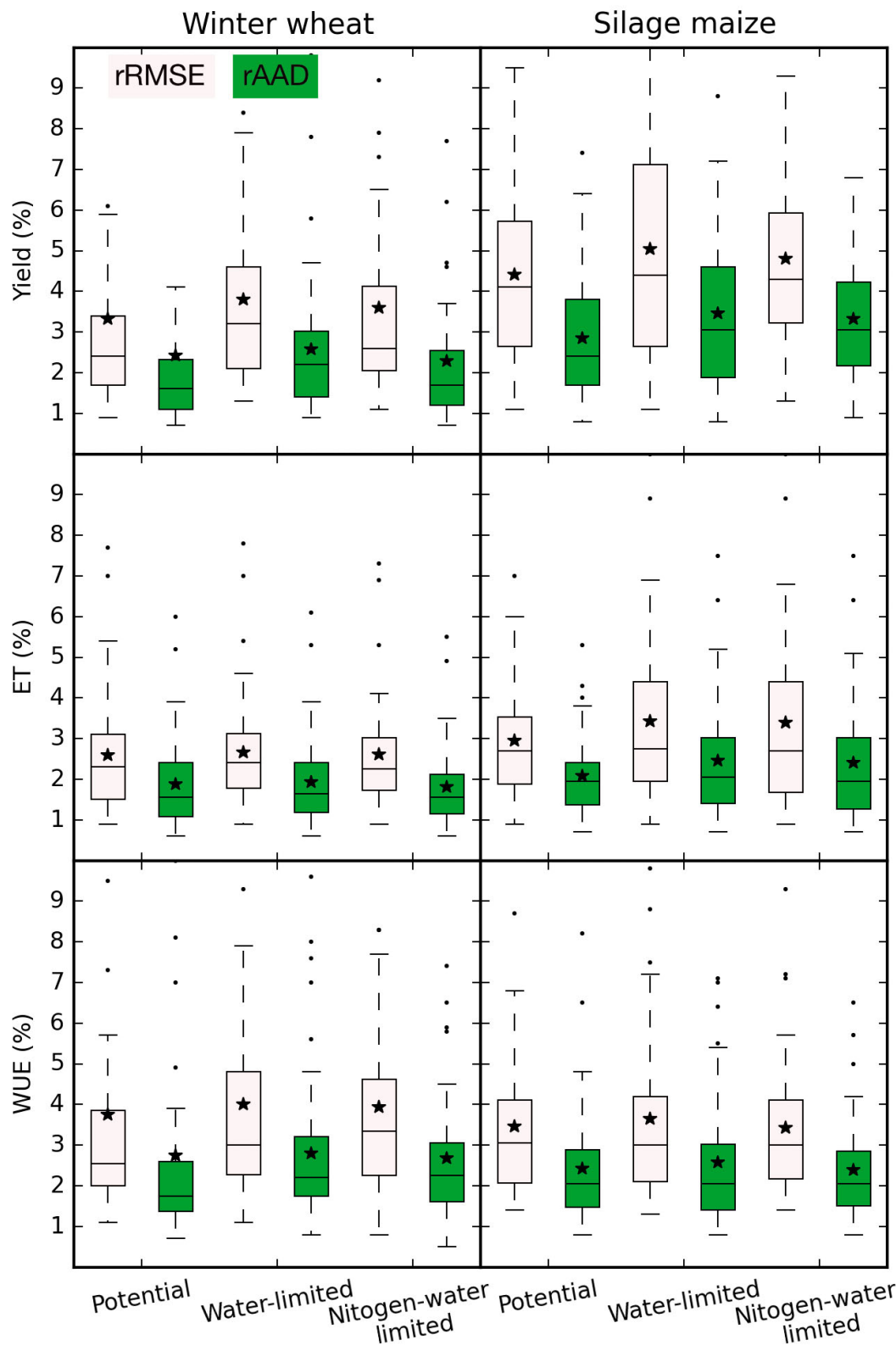

Fig. 9. Variation of relative root mean squared error (rRMSE) and relative average absolute deviation (rAAD) of yield, evapotranspiration (ET), and water use efficiency (WUE) across 3 production conditions, i.e. potential, water limited, and nitrogen+water limited. Boxplots created using values of different models and different resolutions $(10,25,50$, and $100 \mathrm{~km})$. Horizontal line in each box: median; asterisk: mean; edges of box: lower and upper hinges (25th and 75th percentiles, Q1 and Q3); whiskers extend to $\mathrm{Q} 1-1.5 \times$ the inter-quartile range $(\mathrm{IQR})$ and $\mathrm{Q} 3+1.5 \times \mathrm{IQR}$, where $\mathrm{IQR}=$ $1.5 \times(\mathrm{Q} 3-\mathrm{Q} 1)$; dots beyond the whiskers: outliers

conducted a sensitivity analysis between the simulated yield change $\left(\Delta_{\text {Yield }}\right)$ and the change in weather variables $\left(\Delta_{\text {Weather variables }}\right)$. The results showed that the correlations between $\Delta_{\text {Yield }}$ and $\Delta_{\text {Weather variables }}$ were considerably different across models. For winter wheat, half of the models had a negative correlation coefficient, while the other half of the models had a positive correlation coefficient (Fig. S6). For silage maize, the signs were generally consistent among models.

The differences between winter wheat and silage maize across models could also result from the calibration of the phenology-related parameters, especially the cardinal temperatures and thermal time requirement for crop development. We provided the modelers with typical harvest dates for both crops. Winter wheat was harvested based on thermal time requirement to reach maturity, but silage maize was harvested no later than a specified date (20 September). For winter wheat, this implied a shorter growing season and low yield when growing in mountainous areas where temperature and radiation are typically lower, particularly for models calibrated with a low base temperature for development or a short thermal time requirement to reach maturity. On the other hand, for wheat models parameterized with higher base temperature or longer thermal time requirements to reach maturity, a lower yield would be simulated due to the shorter growing season and limited radiation interception. Furthermore, most of the models used the method of radiation use efficiency (RUE) and the dynamics of leaf area to simulate the yields (Table S1). However, the way RUE and leaf area index dynamics were computed differs across models, e.g. a constant versus varying RUE with developmental stage and temperature (Table S1). This could be another reason for the opposite spatial patterns (Mearns et al. 1999, Adam et al. 2011).

\subsection{Relationship between DAE on weather and response variables}

Changing the spatial resolution caused obvious biases $(\Delta)$ in the historical mean weather data, especially in the southwestern mountainous regions (Fig. 5), with a high spatial heterogeneity due to the high terrain differences (Fig. 2). In contrast, the weather conditions in the flat lowland regions were relatively homogeneous, and therefore the aggregation only caused small biases. Since a sin- 

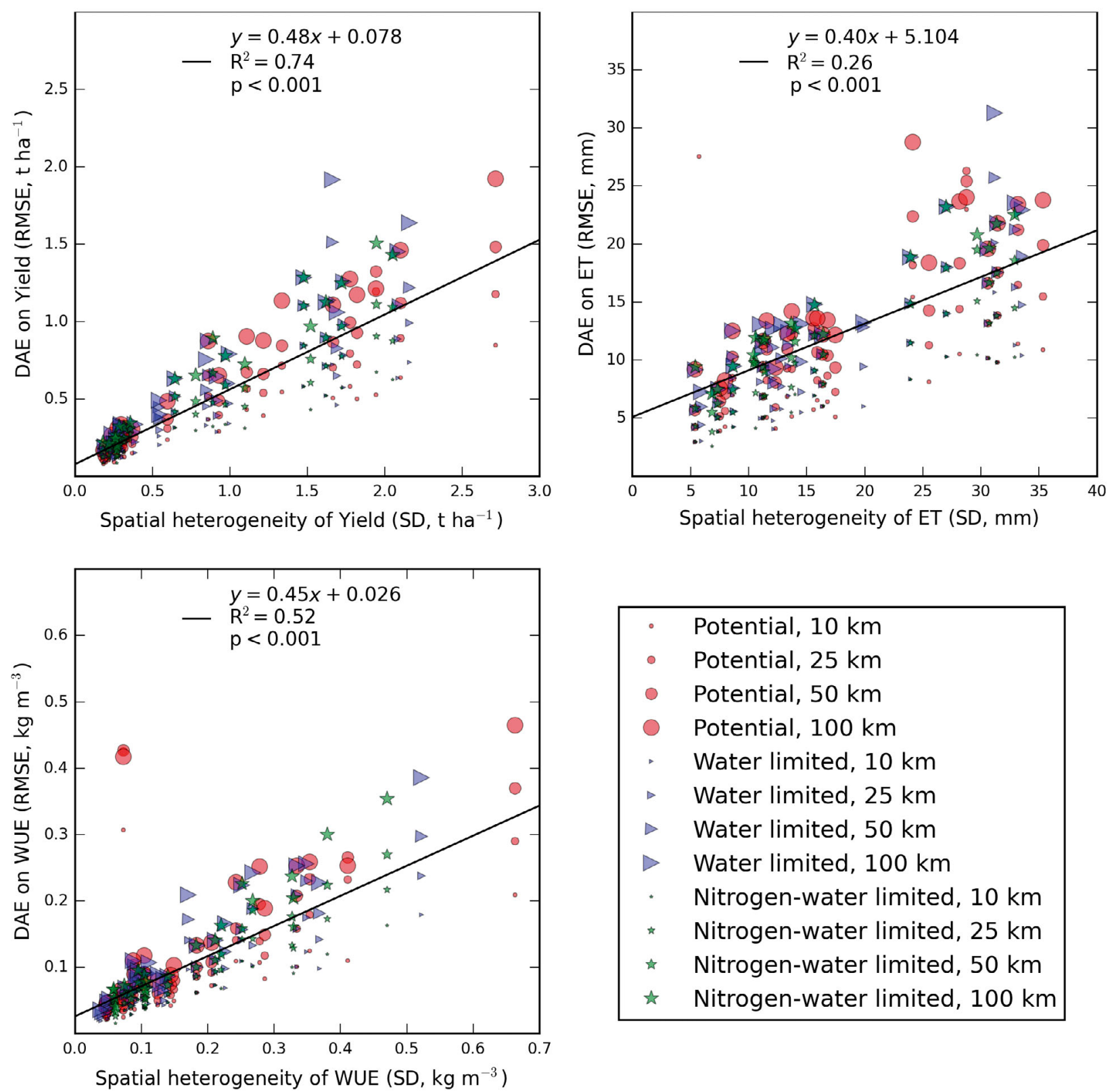

\begin{tabular}{|cl|}
\hline & Potential, $10 \mathrm{~km}$ \\
& Potential, $25 \mathrm{~km}$ \\
& Potential, $50 \mathrm{~km}$ \\
& Potential, $100 \mathrm{~km}$ \\
& Water limited, $10 \mathrm{~km}$ \\
& Water limited, $25 \mathrm{~km}$ \\
& Water limited, $50 \mathrm{~km}$ \\
& Water limited, $100 \mathrm{~km}$ \\
& Nitrogen-water limited, $10 \mathrm{~km}$ \\
& Nitrogen-water limited, $25 \mathrm{~km}$ \\
$\star$ & Nitrogen-water limited, $50 \mathrm{~km}$ \\
& Nitrogen-water limited, $100 \mathrm{~km}$ \\
\hline
\end{tabular}

Fig. 10. Relationships between spatial heterogeneity of simulated response variables for winter wheat (indicated by standard deviation of grid cells at $1 \mathrm{~km}$ resolution, $\mathrm{SD}$ ) and the data aggregation effect (DAE, indicated by root mean squared error [RMSE] across different resolutions). Each point represents a crop model simulation at a specific resolution under a specific production condition. The different production conditions are indicated by different markers and colors. The resolutions or the aggregation levels are indicated by the size of the marker

gle soil profile was used for all grid cells and changing of weather data was the only factor that changed the spatial variability in the simulated results, the changes were well captured by the crop models; thus high correlations were found between the bias in weather data and simulated response variables (Fig. S6). Since averaging was employed to aggregate the data to coarse resolutions, the resultant data were either higher or lower than the original high-resolution data. When the simulated outputs consistently responded to the change in weather variables due to aggregation, the spatial patterns of the biases were similar across different models. In contrast, when the responses were not consistent (linear or non-linear), the spatial pattern of biases varied across different models (Hansen \& Jones 2000). 
4.3. Variation of DAE across production conditions, crops, response variables, and models

The rAAD and rRMSE were used to summarize the impact of DAE for the entire study area. There was little effect of changing production conditions on both rAAD and rRMSE (Fig. 9). The reason could be that including soil water and nitrogen limitations did not introduce much extra spatial heterogeneity for the response variables, and the DAE was mainly determined by the spatial heterogeneity of weather. This may be due to the high input of nitrogen fertilizer prescribed for the simulations, which are consistent with the high input agriculture in Germany and due to the fact that soil data (soil profile with very high water-holding capacity) were kept constant across the whole study area and their effect on the stresses from water and nutrient availability did not considerably vary. Although the water and nitrogen stress decreased the yield, and the nitrogen availability significantly reduced silage maize yield (Figs. 6 \& 7), the decreases were similar across the study area. Thus, very little extra heterogeneity was added to the simulated response variables by adding water and $\mathrm{N}$ limitations to the cropping systems. However, Doherty et al. (2003) found that the effect of changing weather data resolution is stronger for water-limited yield of cotton than for irrigated yields (comparable to potential yield). This is in contrast to our results and may be due to the predominantly summer dry subtropical climate (typical for the cotton belt in the US) and use of actual soil data, which adds spatial heterogeneity when the stress from water availability is strong.

The relative DAE (rAAD and rRMSE) values were only slightly different between the 2 crops. This may be explained by the fact that most of the models involved in this study are generic across crops (Table S1). Typically, some of these models simulate many crops by changing the relevant parameters. When the absolute values of the variables were high, the resultant absolute biases would be high too. Therefore we also computed rAAD and rRMSE to avoid the effect from an absolute yield level (Chambers \& Dunstan 1986). Using the AAD and RMSE rather than the rAAD and rRMSE would conclude that DAE for silage maize is higher than for winter wheat (Fig. S7). This conclusion is in line with Mearns et al. (1999) and Easterling et al. (1998). Mearns et al. (1999) found that the uncertainties in simulating yield of maize and wheat were not ignorable and the uncertainties differed for the 2 crops for the models CERES and EPIC. Easterling et al. (1998) found different DAEs on wheat and hay simulations.
The present study recognized the necessity to distinguish the absolute and relative change in quantifying and comparing the DAE across different crops, which could result in opposite conclusions.

For a specific model, the DAE on different response variables ranked differently. This is in line with Mo et al. (2009), who found that the DAE on gross primary production (GPP) is more significant than that on ET. The differences could result from the different algorithms used to simulate different response variables. For example, for the models in our study, the simulation of yield formation involved more processes than the growing season ET.

The rAAD and rRMSE for different models differed notably from each other. This is caused by the varying spatial heterogeneity of the results simulated by different crop models. The weather data had a consistent spatial pattern which is closely related to the topography of the study area, because the weather data were corrected according to the altitude of the grid cell. However, a certain number of the models simulated fairly homogeneous results, while other models simulated a considerable spatial heterogeneity comparable to the weather data (Figs. S4 \& S5) because of the different sensitivities to weather variables. When the spatial heterogeneity of the response variables was high, the rAAD and rRMSE were correspondingly high, and vice versa (Figs. 10 \& S8). Thus, diverse crop models added uncertainty to the effect of changing the spatial resolution of input data. Hence, identifying the required spatial resolution for impact assessment cannot be made independent of models used, which agrees with Mearns et al. (1999).

We found that the rAAD varied in the same direction but was generally lower than rRMSE. Extremely high changes in only some grid cells resulted in a high rRMSE and a relatively small rAAD. This justified the choice of using 2 indicators to quantify the impacts of input data spatial resolution (Davis \& Dodd 2003). The differences between rAAD and rRMSE indicated that the effect on the loss of hotspot areas was much higher than on changing the average condition of the whole study area when using a coarse spatial resolution (Willmott \& Matsuura 2005).

\subsection{Implication of the results}

Most environmental processes are scale-dependent (Davis et al. 1991, Wu 2004). The spatial resolution used for an impact assessment should be high enough to represent the processes that are important for the 
objective (Atkinson \& Tate 2000). Integrated assessments at regional scales normally target 2 objectives. One is how overall regional aggregates such as regional productivity would be impacted by environmental changes or human interventions. In such a case, the mean or the median of the response variable of the whole study area is of particular interest. This was also investigated by Hoffmann et al. (2015) and Angulo et al. (2013) by comparing the mean and median of the results simulated by weather data at different spatial resolutions in central (Germany) and northern (Finland) Europe. They found that spatial resolution only caused moderate and non-significant changes in response variables. The explanation was that the weather data at coarse resolution would be either higher or lower than the high-resolution values over the same area. The simulated yields were correspondingly higher or lower, because the non-linearity relationships between the simulated yields and weather data were not of significant importance (Hansen \& Jones 2000). Similarly, in our study, changes in resolution of the mean response variables had only small effects, since the higher or lower yields offset each other. Hence, if there is only interest in the regional aggregates of response variables, coarseresolution input data may be sufficient for impact studies in temperate, humid regions as also suggested elsewhere (Easterling et al. 1998, de Wit et al. 2005, Van Bussel et al. 2011, Eyshi Rezaei et al. 2015).

However, importantly, if the emphasis of the impact study is on detecting local hotspot areas (such as croplands which are potentially vulnerable to drought or heat stress; Teixeira et al. 2013, Müller et al. 2014) to support planning for conservation and environmental management (Crossman \& Bryan 2009, Raymond et al. 2009) and climate change impact assessments (Mearns et al. 2004), then aggregation of the input data or use of a coarse resolution could fail to detect hotspot areas. This has been clearly illustrated in the present study where the low-yielding areas disappeared at the lower resolutions. Such DAE is particularly evident in the regions with highly spatial heterogeneity compared to homogeneous regions (Figs. 6 \& 7). Thus, in spatially heterogeneous regions, using input data at a high spatial resolution is desirable (Gimona et al. 2006, Zhao et al. 2015).

\subsection{Limitations of the study and future research needs}

When we created the weather data at different resolutions, varying regional boundaries of grid cells were used. For example, the calculation of the grid cell at $10 \mathrm{~km}$ resolution did not include the $1 \mathrm{~km}$ grid cells in the Netherlands and Belgium, but included the grid cells in other states of Germany. Therefore, a certain magnitude of the response variable changes across the boundary could result from the varying regional boundary. An alternative strategy to conduct the aggregation across the boundary is sticking to the boundary of $1 \mathrm{~km}$ resolution. This method could guarantee the number of $1 \mathrm{~km}$ grid cells being equal at different aggregation levels, but has the disadvantage that coarse-resolution grid cells are not fully covered by the high-resolution grid cells. Currently, there is no agreement on how to cope with this issue. For future studies, the uncertainties from boundary effects should be considered more carefully. In addition to the boundary effects, increasing the temporal resolution of the weather data from monthly to daily may also add uncertainties when interpolated between weather stations, thus affecting the simulated results.

The averaging method was used to aggregate the input weather data. Many other methods such as majority, median, nearest neighbor, bilinear interpolation, central-pixel, and direct interpolation, are frequently used. For example, Bian \& Butler (1999) found that the averaging and median methods could retain the mean but significantly altered the standard deviation, while the central-pixel method altered both statistics on a moderate scale. Carter et al. (1991) directly interpolated weather data of coarse spatial resolution by direct interpolation using data from weather stations that are relevant for crop production according to their altitude. Aggregating the weather data by different methods could change the DAE on simulation of the cropping systems. Although averaging is the most commonly used method and was therefore considered here, the effect of using other methods should be explored more systematically.

Only 1 soil profile was applied in this study. The water holding capacity, initial soil carbon, and nitrogen of the soil profile were relatively high (Table 1). Together with the predominantly temperate, humid climate, this explains why drought was not evident in most of the grid cells and years. Additional spatial heterogeneity in model outputs would be expected by considering soil variability. For example, Angulo et al. (2014) found that the DAE of soil data on the distribution of simulated yields is much higher in dry years than in normal years in NRW, while Eyshi Rezaei et al. (2015) showed that the variability in heat and drought stress of winter wheat in Germany is 
more affected by the variability in soil than by variability in weather conditions. In addition, individual crop models simulated the water and nitrogen cycles differently, implying contrasting responses to soil input variables. The rRMSE and rAAD may have been enhanced with model complexity depending on how the non-linearity of soil processes is handled by individual models. The soil parameters also need to be aggregated or disaggregated to the same resolution as weather data, which also cause biases across the aggregation levels. The response of the crop models to such discrepancy should be considered in upscaling practices. Recently, Zhang et al. (2014) found that higher-resolution soil information could benefit the simulation at the county level, while it made negligible differences in the state of Iowa (USA), an area which is more than 4 times of the size of NRW.

\section{CONCLUSIONS}

In up-scaling crop models from field to larger areas, it is essential to understand the uncertainties introduced due to aggregation of input data. An ideal resolution would be one that is fine enough to provide accurate spatial variability for the specific purpose of the study, while saving computing power and efforts in data assembly and model execution. In this study, we quantified the DAE by 5 metrics and compared DAE across crop models, crops, response variables, and production conditions. The 5 metrics used indicated that the DAE increased with coarsening of the spatial resolution, especially from 1 to $50 \mathrm{~km}$. The DAE on diminishing hotspot areas of the results is stronger than on the average conditions. The DAE varies considerably across models, but only slightly across crops, production conditions, and response variables. The findings of this study can guide crop modelers when choosing the spatial resolution for regional crop modeling and climate change impact assessment in temperate, humid regions with pronounced elevation differences.

Acknowledgements. This study was supported by the BMBF/BMELV project on 'Modeling European Agriculture with Climate Change for Food Security (MACSUR)' (grant no. 2812ERA115). The work was also supported by The Swedish Research Council for Environment, Agricultural Sciences and Spatial Planning (contract 220-2007-1218) and by the strategic funding 'Soil-Water-Landscape' from the faculty of Natural Resources and Agricultural Sciences (Swedish University of Agricultural Sciences). E.T. was supported by the Royal Society of New Zealand and the Climate Changes, Impacts and Implications for New Zealand Project (CCII). We thank the Landesbetrieb Information und
Technik Nordrhein-Westfalen for providing regional yield data and the German Meteorological Service for providing weather data. We are also grateful to Professor Per-Erik Jansson (Royal Institute of Technology in Stockholm) for valuable support linked to the application of the COUPmodel. Comments from 3 reviewers greatly improved the manuscript.

\section{LITERATURE CITED}

Adam M, Van Bussel LGJ, Leffelaar PA, Van Keulen H, Ewert F (2011) Effects of modelling detail on simulated potential crop yields under a wide range of climatic conditions. Ecol Model 222:131-143

Angulo C, Rötter R, Trnka M, Pirttioja N, Gaiser T, Hlavinka P, Ewert F (2013) Characteristic 'fingerprints' of crop model responses to weather input data at different spatial resolutions. Eur J Agron 49:104-114

Angulo C, Gaiser T, Rötter RP, Børgesen CD, Hlavinka P, Trnka M, Ewert F (2014) 'Fingerprints' of four crop models as affected by soil input data aggregation. Eur J Agron 61:35-48

> Asseng S, Keating B, Fillery I, Gregory P and others (1998) Performance of the APSIM-wheat model in Western Australia. Field Crops Res 57:163-179

> Asseng S, Jamieson PD, Kimball B, Pinter P, Sayre K, Bowden JW, Howden SM (2004) Simulated wheat growth affected by rising temperature, increased water deficit and elevated atmospheric $\mathrm{CO}_{2}$. Field Crops Res 85:85-102

Asseng S, Ewert F, Rosenzweig C, Jones JW and others (2013) Uncertainty in simulating wheat yields under climate change. Nat Clim Change 3:827-832

Asseng S, Ewert F, Martre P, Rotter RP and others (2015) Rising temperatures reduce global wheat production. Nat Clim Change 5:143-147

> Atkinson PM, Tate NJ (2000) Spatial scale problems and geostatistical solutions: a review. Prof Geogr 52:607-623

Bergez JE, Chabrier P, Gary C, Jeuffroy MH and others (2013) An open platform to build, evaluate and simulate integrated models of farming and agro-ecosystems. Environ Model Softw 39:39-49

Bian L, Butler R (1999) Comparing effects of aggregation methods on statistical and spatial properties of simulated spatial data. Photogramm Eng Remote Sensing 65: 73-84

- Bormann H, Breuer L, Gräff T, Huisman J, Croke B (2009) Assessing the impact of land use change on hydrology by ensemble modelling (LUCHEM). IV. Model sensitivity to data aggregation and spatial (re-) distribution. Adv Water Resour 32:171-192

Brisson N, Mary B, Ripoche D, Jeuffroy MH and others (1998) STICS: a generic model for the simulation of crops and their water and nitrogen balances. I. Theory and parameterization applied to wheat and corn. Agronomie 18:311-346

> Carter TR, Parry ML, Porter JH (1991) Climatic change and future agroclimatic potential in Europe. Int J Climatol 11: 251-269

> Chambers R, Dunstan R (1986) Estimating distribution functions from survey data. Biometrika 73:597-604

> Conrad Y, Fohrer N (2009) Modelling of nitrogen leaching under a complex winter wheat and red clover crop rotation in a drained agricultural field. Phys Chem Earth Parts ABC 34:530-540

> Crossman ND, Bryan BA (2009) Identifying cost-effective 
hotspots for restoring natural capital and enhancing landscape multifunctionality. Ecol Econ 68:654-668

Datensammlung KTBL (Kuratorium für Technik und Bauwesen in der Landwirtschaft) (2008) Betriebsplanung Landwirtschaft 2008/09 - Daten für die Betriebsplanung in der Landwirtschaft. KTBL, Darmstadt

$>$ Davis LL, Dodd BG (2003) Item exposure constraints for testlets in the verbal reasoning section of the MCAT. Appl Psychol Meas 27:335-356

Davis FW, Quattrochi DA, Ridd MK, Lam NN and others (1991) Environmental analysis using integrated GIS and remotely sensed data: some research needs and priorities. Photogramm Eng Remote Sensing 57:689-697

$>$ de Wit AJW, Boogaard HL, van Diepen CA (2005) Spatial resolution of precipitation and radiation: the effect on regional crop yield forecasts. Agric For Meteorol 135: 156-168

> Del Grosso SJ, Parton WJ, Mosier AR, Walsh MK, Ojima DS, Thornton P (2006) DAYCENT national-scale simulations of nitrous oxide emissions from cropped soils in the United States. J Environ Qual 35:1451-1460

> Di Vittorio AV, Miller NL (2014) Reducing the impact of model scale on simulated, gridded switchgrass yields. Environ Model Softw 51:70-83

> Doherty RM, Mearns LO, Reddy KR, Downton MW, McDaniel L (2003) Spatial scale effects of climate scenarios on simulated cotton production in the southeastern USA. Clim Change 60:99-129

> Durman C, Gregory J, Hassell D, Jones R, Murphy J (2001) A comparison of extreme European daily precipitation simulated by a global and a regional climate model for present and future climates. QJR Meteorol Soc 127: 1005-1015

> Easterling WE, Weiss A, Hays CJ, Mearns LO (1998) Spatial scales of climate information for simulating wheat and maize productivity: the case of the US Great Plains. Agric For Meteorol 90:51-63

Eitzinger J, Thaler S, Schmid E, Strauss F and others (2013) Sensitivities of crop models to extreme weather conditions during flowering period demonstrated for maize and winter wheat in Austria. J Agric Sci 151:813-835

Ewert F, van Ittersum MK, Heckelei T, Therond O, Bezlepkina I, Andersen E (2011) Scale changes and model linking methods for integrated assessment of agrienvironmental systems. Agric Ecosyst Environ 142:6-17

Eyshi Rezaei E, Siebert S, Ewert F (2015) Impact of data resolution on heat and drought stress simulated for winter wheat in Germany. Eur J Agron 65:69-82

Falloon P, Challinor A, Dessai S, Hoang L, Johnson J, Koehler AK (2014) Ensembles and uncertainty in climate change impacts. Front Environ Sci 2:33

> Folberth C, Yang H, Wang X, Abbaspour KC (2012) Impact of input data resolution and extent of harvested areas on crop yield estimates in large-scale agricultural modeling for maize in the USA. Ecol Model 235-236:8-18

Gaiser T, Perkons U, Küpper PM, Kautz T and others (2013) Modeling biopore effects on root growth and biomass production on soils with pronounced sub-soil clay accumulation. Ecol Model 256:6-15

GDNRW (Geologischer Dienst Nordrhein-Westfalen) (2001) AGBK50-Allgemeine Informationen zur Bodenkarte 1: 50 000. Arbeitsgruppe BK50, Geologischer Dienst Nordrhein-Westfalen, Krefeld

Gimona A, Birnie R, Sibbald A (2006) Scaling up of a mechanistic dynamic model in a GIS environment to model temperate grassland production at the regional scale. Grass Forage Sci 61:315-331
Glemnitz M, Wurbs A, Roth R (2011) Derivation of regional crop sequences as an indicator for potential GMO dispersal on large spatial scales. Ecol Indic 11:964-973

Haas E, Klatt S, Fröhlich A, Kraft P and others (2013) LandscapeDNDC: a process model for simulation of biosphereatmosphere-hydrosphere exchange processes at site and regional scale. Landsc Ecol 28:615-636

Hansen JW, Jones JW (2000) Scaling-up crop models for climate variability applications. Agric Syst 65:43-72

Hoffmann H, Zhao G, van Bussel LGJ, Enders A and others (2015) Variability of spatial aggregation effects of climate data on regional yield simulation by crop models for a selected region in Germany. Clim Res 65:53-69

Holzworth DP, Huth NI, deVoil PG, Zurcher EJ and others (2014) APSIM - evolution towards a new generation of agricultural systems simulation. Environ Model Softw 62: 327-350

Jansson PE, Karlberg L (2001) Coupled heat and mass transfer model for soil-plant-atmosphere systems. Royal Institute of Technology, Department of Civil and Environmental Engineering, Stockholm

Jones J (1993) Decision support systems for agricultural development. In: Penning de Vries F, Teng P, Metselaar $\mathrm{K}$ (eds) Systems approaches for agricultural development. Springer, Dordrecht, p 459-471

Jones JW, Hoogenboom G, Porter C, Boote K and others (2003) The DSSAT cropping system model. Eur J Agron 18:235-265

Kaspar F, Müller-Westermeier G, Penda E, Mächel H, Zimmermann K, Kaiser-Weiss A, Deutschländer T (2013) Monitoring of climate change in Germany - data, products and services of Germany's National Climate Data Centre. Adv Sci Res 10:99-106

Keating BA, Carberry PS, Hammer GL, Probert ME and others (2003) An overview of APSIM, a model designed for farming systems simulation. Eur J Agron 18:267-288

Kersebaum KC (2007) Modelling nitrogen dynamics in soil-crop systems with HERMES. In: Kersebaum KC, Hecker JM, Mirschel W, Wegehenkel M (eds) Modelling water and nutrient dynamics in soil-crop systems. Springer, p 147-160

Kersebaum K (2011) Special features of the HERMES model and additional procedures for parameterization, calibration, validation, and applications. In: Ahuja LR, Ma L (eds) Methods of introducing system models into agricultural research. Advances in agricultural systems modeling 2. ASA, CSSA, SSSA, Madison, WI, p 65-94

Kraus D, Weller S, Klatt S, Haas E, Wassmann R, Kiese R, Butterbach-Bahl K (2015) A new LandscapeDNDC biogeochemical module to predict $\mathrm{CH}_{4}$ and $\mathrm{N}_{2} \mathrm{O}$ emissions from lowland rice and upland cropping systems. Plant Soil 386:125-149

Mearns LO, Mavromatis T, Tsvetsinskaya E, Hays C, Easterling W (1999) Comparative responses of EPIC and CERES crop models to high and low spatial resolution climate change scenarios. J Geophys Res Atmos 104: 6623-6646

> Mearns LO, Easterling W, Hays C, Marx D (2001) Comparison of agricultural impacts of climate change calculated from high and low resolution climate change scenarios. I. The uncertainty due to spatial scale. Clim Change 51: 131-172

> Mearns LO, Carbone G, Doherty RM, Tsvetsinskaya E, McCarl BA, Adams RM, McDaniel L (2004) The uncertainty due to spatial scale of climate scenarios in integrated assessments: an example from U.S. agriculture. Integr Assess 4:225-235 
Meentemeyer V (1989) Geographical perspectives of space, time, and scale. Landsc Ecol 3:163-173

Mo X, Liu S, Chen DAN, Lin Z, Guo R, Wang KUN (2009) Grid-size effects on estimation of evapotranspiration and gross primary production over a large Loess Plateau basin, China. Hydrol Sci J 54:160-173

> Müller C, Waha K, Bondeau A, Heinke J (2014) Hotspots of climate change impacts in sub-Saharan Africa and implications for adaptation and development. Glob Change Biol 20:2505-2517

Mummery D, Battaglia M (2002) Data input quality and resolution effects on regional and local scale Eucalyptus globulus productivity predictions in north-east Tasmania. Ecol Model 156:13-25

Nendel C, Wieland R, Mirschel W, Specka X, Guddat C, Kersebaum K (2013) Simulating regional winter wheat yields using input data of different spatial resolution. Field Crops Res 145:67-77

Olesen JE, Bøcher PK, Jensen T (2000) Comparison of scales of climate and soil data for aggregating simulated yields of winter wheat in Denmark. Agric Ecosyst Environ 82: 213-228

> Palosuo T, Kersebaum KC, Angulo C, Hlavinka P and others (2011) Simulation of winter wheat yield and its variability in different climates of Europe: a comparison of eight crop growth models. Eur J Agron 35:103-114

$>$ Porter JR, Semenov MA (2005) Crop responses to climatic variation. Philos Trans R Soc Lond B Biol Sci 360: 2021-2035

Posselt R, Müller R, Stöckli R, Trentmann J (2011) CM SAF surface radiation MVIRI Data Set 1.0-Monthly means/ daily means/hourly means. Satellite application facility on climate monitoring. Available at http://dx.doi.org/10. 5676/EUM_SAF_CM/RAD_MVIRI/V001

Raes D, Steduto P, Hsiao TC, Fereres E (2009) AquaCropthe FAO crop model to simulate yield response to water. II. Main algorithms and software description. Agron J 101:438-447

Rauthe M, Steiner H, Riediger U, Mazurkiewicz A, Gratzki A (2013) A Central European precipitation climatology. I. Generation and validation of a high-resolution gridded daily data set (HYRAS). Meteorol Z 22:235-256

Raymond CM, Bryan BA, MacDonald DH, Cast A, Strathearn S, Grandgirard A, Kalivas T (2009) Mapping community values for natural capital and ecosystem services. Ecol Econ 68:1301-1315

Resop JP, Fleisher DH, Timlin DJ, Reddy VR (2014) Biophysical constraints to potential production capacity of potato across the U.S. eastern seaboard region. Agron J 106: 43-56

Rötter RP, Carter TR, Olesen JE, Porter JR (2011) Cropclimate models need an overhaul. Nat Clim Change 1: 175-177

Schulze R (2000) Transcending scales of space and time in impact studies of climate and climate change on agrohydrological responses. Agric Ecosyst Environ 82:185-212

Siebert S, Ewert F (2012) Spatio-temporal patterns of phenological development in Germany in relation to temperature and day length. Agric For Meteorol 152:44-57

Steduto P, Hsiao TC, Raes D, Fereres E (2009) AquaCropThe FAO crop model to simulate yield response to water. I. Concepts and underlying principles. Agron J 101: 426-437

Tao F, Zhang Z (2013) Climate change, wheat productivity and water use in the North China Plain: a new superensemble-based probabilistic projection. Agric For Mete- orol 170:146-165

Tao F, Yokozawa M, Zhang Z (2009) Modelling the impacts of weather and climate variability on crop productivity over a large area: a new process-based model development, optimization, and uncertainties analysis. Agric For Meteorol 149:831-850

Teixeira EI, Fischer G, van Velthuizen H, Walter C, Ewert F (2013) Global hot-spots of heat stress on agricultural crops due to climate change. Agric For Meteorol 170: 206-215

Tsvetsinskaya EA, Mearns LO, Mavromatis T, Gao W, McDaniel L, Downton MW (2003) The effect of spatial scale of climatic change scenarios on simulated maize, winter wheat, and rice production in the southeastern United States. In: Mearns L (ed) Issues in the impacts of climate variability and change on agriculture. Springer, Netherlands, p 37-71

> Van Bussel LGJ, Ewert F, Leffelaar PA (2011) Effects of data aggregation on simulations of crop phenology. Agric Ecosyst Environ 142:75-84

van Ittersum MK, Leffelaar P, Van Keulen H, Kropff M, Bastiaans L, Goudriaan J (2003) On approaches and applications of the Wageningen crop models. Eur J Agron 18: 201-234

> Vanuytrecht E, Raes D, Steduto P, Hsiao TC and others (2014) AquaCrop: FAO's crop water productivity and yield response model. Environ Model Softw 62:351-360

Wang E, Robertson MJ, Hammer GL, Carberry PS and others (2002) Development of a generic crop model template in the cropping system model APSIM. Eur J Agron 18:121-140

Watson J, Challinor A (2013) The relative importance of rainfall, temperature and yield data for a regional-scale crop model. Agric For Meteorol 170:47-57

Webber H, Gaiser T, Ewert F (2014) What role can crop models play in supporting climate change adaptation decisions to enhance food security in Sub-Saharan Africa? Agric Syst 127:161-177

Williams JR (1995) The EPIC model. In: Singh V (ed) Computer models of watershed hydrology. Water Resources Publications, Highlands Ranch, CO, p 909-1000

Williams J, Renard K, Dyke P (1983) EPIC: a new method for assessing erosion's effect on soil productivity. J Soil Water Conserv 38:381-383

Willmott CJ, Matsuura K (2005) Advantages of the mean absolute error (MAE) over the root mean square error (RMSE) in assessing average model performance. Clim Res 30:79-82

> Wu J (2004) Effects of changing scale on landscape pattern analysis: scaling relations. Landscape Ecol 19:125-138

Yeluripati JB, Van Oijen M, Wattenbach M, Neftel A, Ammann A, Parton W, Smith P (2009) Bayesian calibration as a tool for initialising the carbon pools of dynamic soil models. Soil Biol Biochem 41:2579-2583

Zhang X, Sahajpal R, Manowitz DH, Zhao K and others (2014) Multi-scale geospatial agroecosystem modeling: a case study on the influence of soil data resolution on carbon budget estimates. Sci Total Environ 479-480: 138-150

Zhao G, Bryan BA, King D, Luo Z and others (2013) Largescale, high-resolution agricultural systems modeling using a hybrid approach combining grid computing and parallel processing. Environ Model Softw 41:231-238

Zhao G, Siebert S, Enders A, Eyshi Rezaei E, Yan C, Ewert F (2015) Demand for multi-scale weather data for regional crop modelling. Agric For Meteorol 200:156-171 